\title{
ADENOMA METANÉFRICO
}

\section{METANEPHRIC ADENOMA}

\author{
Ana Sayuri Ota, AsCBC-RJ' ${ }^{1}$; Flávio Antônio de Sá Ribeiro, TCBC-RJ² \\ Baltazar de Araújo Fernandes, TCBC-RJ ${ }^{3}$
}

\section{INTRODUÇÃO}

$\mathrm{O}$ adenoma metanefrico é um tumor raro, incluído na classe dos tumores epiteliais renais benignos. Geralmente é detectado em adultos e ocasionalmente em crianças, com excelente prognóstico. Até 1999, cerca de 100 casos foram relatados na literatura.

O objetivo do presente trabalho é relatar o caso de uma paciente com volumoso tumor renal à direita, com características clínicas e radiológicas não específicas e diagnóstico definitivo somente estabelecido pelo estudo histopatológico.

\section{RELATO DO CASO}

Paciente do sexo feminino, 49 anos de idade, previamente saudável, passou a apresentar dor abdominal difusa predominante em flanco direito, em cólica, intermitente, de média intensidade. Evoluiu com episódio de hematúria e febre com calafrios, que regrediram espontaneamente. Referia emagrecimento de cerca de $8 \mathrm{Kg}$ em dois meses, que atribuía à dieta hipocalórica voluntária.

Ao exame encontrava-se em bom estado geral e nutricional, normocorada, afebril, sem adenomegalias periféricas palpáveis. $\mathrm{O}$ abdome era globoso, flácido, indolor a palpação superficial, com massa arredondada, de cerca de $14 \times 10 \mathrm{~cm}$, firme, fixa, localizada em flanco direito, respeitando a linha média.

Os exames laboratoriais evidenciavam 3.270 leucócitos, hematócrito de 39,2\%, VHS de 3mm. O exame de urina apresentava $\mathrm{pH}$ de 6,5 , densidade de 1.015 e sem elementos anormais. Foi sugerida a hipótese de hipernefroma.

Ultra-sonografia abdominal revelou volumosa massa renal heterogênea, bem delimitada, medindo $14 \times 10 \mathrm{~cm}$ nos maiores eixos, ocupando terço médio e inferior do rim direito. O polo superior deste rim tem aspecto normal. A tomografia computadorizada confirmou a presença de volumosa massa em rim direito (Figura 1).

Foi realizada nefrectomia direita e o exame histopatológico revelou adenoma metanefrico (Figura 2).

A paciente permanece em acompanhamento ambulatorial, assintomática.

\section{DISCUSSÃo}

O adenoma metanéfrico é um tumor raro, recentemente reconhecido como um singular tumor benigno renal. É geralmente detectado em adultos e ocasionalmente em crianças. São mais freqüentes em pacientes do sexo feminino numa relação de 2:1. A média da idade dos pacientes acometidos é

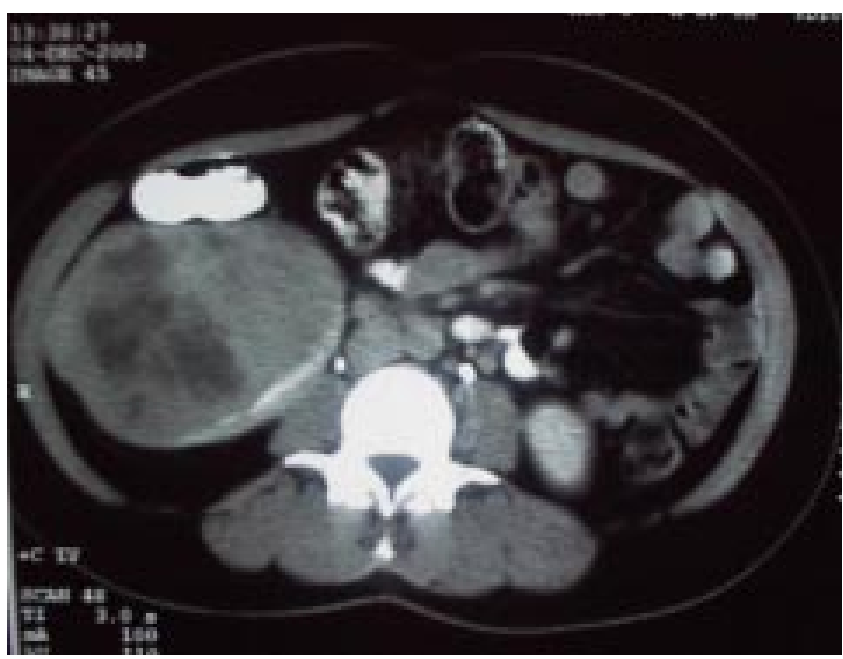

Figura 1 - Tomografia computadorizada de abdome evidenciando volumosa massa em topografia renal direita.

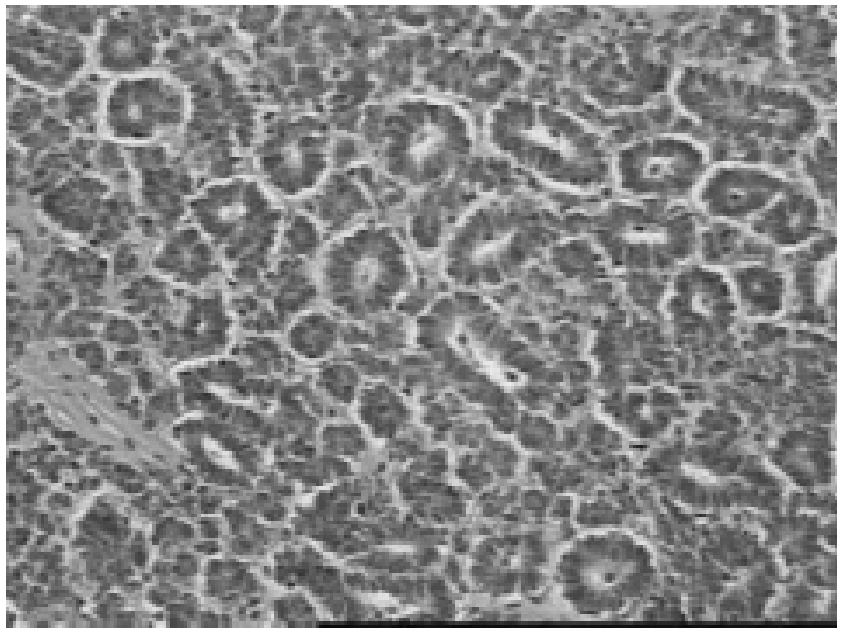

Figura 2: Adenoma Metanéfrico - Estrutura tubular (aumento de $100 x)$.

1. Residente de Cirurgia Geral do Hospital Geral de Bonsucesso

2. Cirurgião Geral da Primeira Clínica Cirúrgica do Hospital Geral de Bonsucesso

3. Chefe da Primeira Clínica Cirúrgica do Hospital Geral de Bonsucesso 
de 41 anos, com variação de cinco a 83 anos e a média de tamanho do tumor é de $5,5 \mathrm{~cm}$, com uma variação de $0,3 \mathrm{a} 15 \mathrm{~cm} .^{2}$ Não há preponderância racial. Até 1999, cerca de 100 casos foram relatados na literatura.

O neoplasma metanéfrico pode ser composto de pequenas células epiteliais ou de estroma benigno ou ambos, e são denominados adenoma metanefrico, tumor estromal metanéfrico, ou adenofibroma metanéfrico, respectivamente. Estes tumores geralmente tem comportamento benigno. $\mathrm{O}$ adenoma metanéfrico é histogeneticamente relacionado ao Tumor de Wilms e é morfologicamente e imunofenotipicamente idêntico ao tumor de Wilms maduro e restos nefrogênicos. ${ }^{3}$

Os sinais e sintomas comumente presentes incluem dor, hematúria, massa palpável e policitemia. ${ }^{4}$ Entretanto, em aproximadamente $50 \%$ dos casos, estes neoplasmas representam achados acidentais e são descobertos durante avaliação de outras doenças. O diagnóstico clínico é difícil, pois os sintomas clássicos sugerem o diagnóstico de hipernefroma. Existe, porém, uma alta incidência de policitemia nos adenomas renais em comparação com outras doenças renais já reportadas.

Macroscopicamente, os adenomas metanéfricos são geralmente tumores bem circunscritos e não encapsulados. Pode estar presente uma fina e descontínua pseudocápsula. Estes neoplasmas podem variar de $3 \mathrm{~mm}$ a $15 \mathrm{~cm}$ em seu maior diâmetro, embora a maioria seja menor que $1 \mathrm{~cm}$. A vasta maioria dos tumores são unilaterais e unifocais.

Deste modo, um curso clínico uniformemente benigno tem sido associado com o adenoma metanéfrico. ${ }^{5}$ Porém, dada a sua identificação recente e a falta de meios de diagnósticos clínicos, radiográficos e citológicos definitivos, o diagnóstico do adenoma metanéfrico tem sido feito através de estudo histológico, imunohistoquímico e genético, porque a maioria dos pacientes, se não todos, necessitam excisão cirúrgica do tumor devido á preocupação relacionada a malignidade.

\begin{abstract}
Metanephric adenoma is a recently described, rare and benign renal tumor that generally occurs in adults and has an excellent prognosis. Pain, hematuria and palpable mass are the most commonly presented signs. We report the case of a 49-year old female with a 14-cm solitary right renal tumor. Radiological features of the tumor were non-specific and histopathological examination was essential to establish a definitive diagnosis (Rev. Col. Bras. Cir. 2005; 32(5): 348-349).
\end{abstract}

Key words: Adenoma; Kidney neoplasms/pathology; Surgery.

\section{REFERÊNCIAS}

1. Pins MR, Jones EC, Martul EV, et al. Metanephric adenoma-like tumors of the kidney: report of 3 malignancies with emphasis on discriminating features. Arch Pathol Lab Med. 1999;123(5):415-20.

2. Davis CJ, Barton JH, Sesterhenn IA, et al. Metanephric adenoma. Clinicopathological study of fifty patients. Am J Surg Pathol.1995;19(10):1101-14.

3. Muir TE, Cheville JC, Lager DJ. Metanephric adenoma, nephrogenic rests and wilms' tumor: a histologic and immunophenotypic comparison. Am J Surg Pathol. 2001; 25(10):1290-6.
4. Walsh PC. Benign renal tumors. In: Campbell MF, Walsh PC, Retik AB, editors. Campbell's Urology. $8^{\text {th }}$ ed. Philadelphia: W.B. Saunders; 2002. p. 2679-85.

5. Renshaw AA, Freyer DR, Hammers YA. Metastatic metanephric adenoma in child. Am J Surg Pathol. 2000; 24(4):570-4.

Endereço para correspondência:

Flávio Antônio de Sá Ribeiro

Av. Nossa Senhora de Copacabana, 680 / 1009

Copacabana

22071-000 - Rio de Janeiro - RJ 